\title{
SUSCEPTIBILIDADE ANTIMICROBIANA DE CEPAS DE Escherichia coli ISOLADAS DE AVES CONDENADAS POR COLIBACILOSE
}

\author{
[Antimicrobial susceptibility of Escherichia coli isolated from poultry]
}

\author{
Leandro L. Nepomuceno ${ }^{1}$, Karina A. Maciel ${ }^{1}$, Helcileia D. Santos ${ }^{1}$, Adriana C. Floresta ${ }^{2}$, Cléverson \\ Baum $^{2}$, Francisca Elda F. Dias ${ }^{1}$, Leonor C. L. Nepomuceno ${ }^{3}$, Valmárcia R. dos Reis ${ }^{1}$, Cristiane A. \\ Nascimento $^{1}$, Bruna Alexandrino ${ }^{1}$, Sílvia Minharro $^{1 *}$ \\ 1 Universidade Federal do Tocantins, Araguaína, TO, Brasil. \\ 2 Ministério da Agricultura, Pecuária e Abastecimento, SISA, Palmas, TO, Brasil \\ 3 Centro Universitário do Estado do Pará, CESUPA, Brasil.
}

\begin{abstract}
RESUMO - Este estudo tem por objetivo avaliar o perfil de susceptibilidade antimicrobiana de 130 cepas de Escherichia coli isoladas de aves condenadas por colibacilose pela Inspeção Federal no estado do Tocantins, procedentes dos estados de Distrito Federal (DF), Goiás (GO), São Paulo (SP) e Tocantins (TO), a realização do teste de sensibilidade aos antimicrobianos (TSA) seguiu a metodologia proposta por CLSI. Os resultados mostraram que $76 \%$ e $72 \%$ das cepas provenientes do estado do GO e TO, respectivamente, apresentaram sensibilidade aos antimicrobianos testados. Enquanto as cepas isoladas no DF e SP apresentaram sensibilidade de $65 \%$ e $62 \%$ respectivamente. Quando analisado o perfil de sensibilidade dos grupos de antimicrobianos formados, observou-se que a maioria das amostras foram sensíveis, com maior destaque ao grupo das pleuromutilinas (93\%), seguidos dos aminoglicosídeos (88\%) e quinolonas/fluoroquinolonas (77\%). Dentre as cepas isoladas, $30,76 \%$ apresentaram resistência a pelo menos dois antimicrobianos testados, recomendados para tratamento de aves. Nas condições experimentais deste trabalho, entre os antimicrobianos testados, apenas ceftioflur, florfenicol, ciprofloxacina, trimethoprim + sulfametoxazol, gentamicina, amoxicilina + ácido clavulânico foram indicados para tratamento de E. coli em frangos. E apensar da utilização de antimicrobianos não ter se mostrado um problema em nossos estudos nos estados estudados a multirresistência obtida ressalta a importância de uso criterioso e controlado destes fármacos na avicultura.
\end{abstract}

Palavras-Chave: Inspeção; Cepas; Multirresistência.

\begin{abstract}
The present study aims to evaluate the antimicrobial susceptibility profiles of 130 strains of Escherichia coli isolated from viscera and upper respiratory tract poultry condemned for colibacillosis for Federal Inspection in the state of Tocantins. The poultry analyzed in this study were originated from the states of the Distrito Federal (DF), Goiás (GO), São Paulo (SP) and Tocantins (TO), to perform susceptibility testing antimicrobial (TSA) follow the methodology proposed by CLSI. The results showed that $76 \%$ and $72 \%$ of cepas coming from the State GO and TO, respectively, showed sensitivity to antibiotics tested. While the strains isolated in DF and SP showed sensitivity of $65 \%$ and $62 \%$ respectively. When analyzed the sensitivity profile of the formed groups, it was observed that most strains were susceptible, most notably the group of pleuromutilins $(93 \%)$, followed by aminoglycosides (88\%) and quinolones / fluoroquinolones (77\%). Among the isolated cepas, $30.76 \%$ had multidrug resistance to antimicrobials. In the experimental conditions this work, among the antibiotics tested, only ceftioflur, florfenicol, ciprofloxacin, trimethoprim + sulphamethoxazole, gentamicin, amoxicillin + clavulanic acid are indicated for treating E. coli in chickens,. From the data presented the use of antibiotics has not become a problem in the poultry farming since the antibiotics tested were mostly efficient on E. coli.
\end{abstract}

Keywords: Inspection; Strains; Multidrug Resistance.

\footnotetext{
* Autor para correspondência. E-mail: minharro@uft.edu.br Recebido: 28 de outubro de 2015.

Aceito para publicação: 15 de janeiro de 2016
} 


\section{INTRODUÇÃO}

O Brasil é o terceiro maior produtor mundial de aves de corte, liderando o ranque de exportação, contribuindo com renda de 78.392.941 US\$ e produzindo um total de 30.653 .340 toneladas de carne de frango industrializada entre julho de 2014 a julho de 2015 (Agrostat Brasil, 2015).

Com o crescente aumento da população, a demanda por alimento cresce em proporção exponencial, exercendo uma maior pressão na produção de alimentos. Tais exigências levam os produtores a adotarem um sistema de produção intensivo, que maximiza a produção animal em uma pequena área (Fiorentino et al., 2012).

No entanto, a produção animal em uma elevada densidade pode acarretar em estresse para os animais, afetando sua imunidade e rompendo o equilíbrio microbiológico do ambiente e do animal. A partir deste desequilíbrio podem sugerir enfermidades infeciosas (Menin et al., 2008; Rocha, 2010).

Dentre estes patógenos, a Escherichia coli (E. coli) assume grande importância, por estar associada a infecções primárias e secundárias, bem como ao elevado índice de resistência a antimicrobianos (Souza et al., 2004). A mesma pode causar quadros clínicos de onfalite, salpingite, aerossaculite, septicemia e principalmente enterites, que influenciam diretamente no ganho de peso do animal, convergindo em baixo lucro para o produtor (Machado et al., 2013).

A evolução e a disseminação de micro-organismos resistentes aos antimicrobianos são resultados da pressão selecionadora imposta pelo homem, seja pelas prescrições desnecessárias desses medicamentos, pelo uso incorreto em tratamentos sem diagnóstico estabelecido, uso de medicamento empírico ou resíduo de antimicrobianos no meio ambiente (Levin \& Baquero \& Johnsen, 2014; Weber et al., 2015; Dheilly et al., 2013).

As bactérias tem capacidade de transferir seu material genético para outras, contribuindo para a disseminação de genes de resistência entre as populações. Desta maneira, a resistência aos antimicrobianos limitam as possibilidades terapêuticas (Cárdenas-Perea et al., 2014).

A resistência antimicrobiana é um problema com graves implicações clínicas, produtiva e para a saúde pública, portanto, o presente estudo teve por objetivo avaliar o perfil de susceptibilidade antimicrobiana de cepas de E. coli isoladas de vísceras e do trato aéreo superior de aves condenadas sob inspeção no estado do Tocantins.

\section{MATERIAL E MÉTODOS}

Foram obtidas 130 cepas de E. coli isoladas de fígado, coração e suabes de trato aéreo superior (traqueia, fenda palatina e sacos aéreos) de aves comerciais condenadas por lesões características de colibacilose (aerossaculite, pericardite e hepatite) provenientes dos estados de Distrito Federal ( $\mathrm{n}=$ 27), Goiás $(n=66)$, São Paulo $(n=12)$ e Tocantins $(\mathrm{n}=25)$, abatidas sob serviço de Inspeção Federal no estado do Tocantins.

Suabes e fragmentos de órgãos foram inoculados em Caldo Selenito Cistina e incubados a $37^{\circ} \mathrm{C}$ por 24 horas. Após incubação, o material foi semeado em placa contendo ágar MacConkey, incubado a 37 ${ }^{\circ} \mathrm{C}$ por 24 horas. As colônias com características típicas de $E$. coli foram confirmadas através de provas bioquímicas conforme a metodologia descrita por Krieg \& Holt (1984).

Para determinação do perfil de resistência antimicrobiana, o método de difusão em disco de ágar Muller-Hinton foi testado de acordo com CLSI (2012), utilizando cepa de referência $E$. coli ATCC 25922. Foram utilizados os seguintes antimicrobianos com as respectivas concentrações, meropenem - $10 \mu \mathrm{g}$, sulfonamida - 300 $\mathrm{g}$, enrofloxacina - $5 \mu \mathrm{g}$, doxiciclina - 30 $\mathrm{g}$, ciprofloxacina - $5 \mu \mathrm{g}$, tetraciclina - $30 \mu \mathrm{g}$, penicilina $\mathrm{g}-10 \mathrm{u}$, ceftioflur - 30 $\mu \mathrm{g}$, trimethoprim +

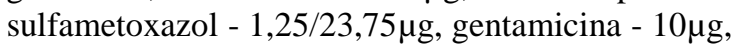

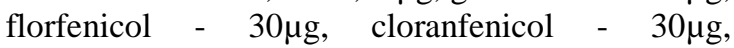

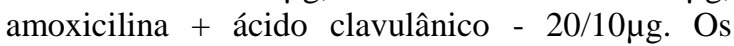
diâmetros das zonas de inibição foram medidos (milímetro) e as amostras foram classificadas em sensíveis, intermediárias ou resistentes aos antimicrobianos testados, de acordo com a tabela proposta pelo fabricante (Laborclin, Bio-Rad). Para efeito de resultados, consideraram-se apenas as categorias sensíveis e resistentes. Nesta última, contabilizaram-se os resultados de intermediários e resistentes. A eficácia (sensibilidade) dos antimicrobianos baseou-se no critério adotado por Salehi \& Bonab (2006), Saberfar et al. (2008), Sahoo et al. (2012) e Rahimi (2013) que consideram o resultado positivo do antibiograma (ou seja, houve inibição do crescimento microbiano) para determinada droga atingiu, no mínimo, $70 \%$ das amostras.

Para a interpretação foi utilizado análise estatística dos dados realizando a análise bivariada, na qual foi feito cruzamento das variáveis independentes, isto é, as variáveis referentes a amostra e a unidade federativa. A significância estatística das associações foi calculada através do teste do QuiQuadrado $\left(\mathrm{X}^{2}\right)$, com correção de Yates, ou teste exato de Fischer nos casos em que a amostra era pequena. Utilizou-se o programa estatístico Epi- 
info versão, 3.5, as associações foram consideradas significativas quando $\mathrm{p}<0,05$.

\section{RESULTADOS E DISCUSSÃO}

Quando analisado o perfil de sensibilidade das cepas bacterianas frente aos grupos de antimicrobianos (Tabela 1), observou-se que a maioria das amostras foram sensíveis, com maior destaque ao grupo das pleuromutilinas (93\%), seguidos dos aminoglicosídeos (88\%) e quinolonas/fluoroquinolonas (77\%).

Tabela 1. Frequência de susceptibilidade antimicrobiana de 130 cepas de Escherichia coli isoladas de trato respiratório superior e vísceras condenadas com suspeitas clínicas de colibacilose oriunda de aves abatidas sob inspeção no Estado do Tocantins entre agosto de 2010 a junho de 2012.

\begin{tabular}{|c|c|c|c|c|}
\hline \multirow[t]{2}{*}{ Grupos } & \multicolumn{2}{|c|}{ Sensível } & \multicolumn{2}{|c|}{ Resistente } \\
\hline & $\mathrm{N}^{\mathrm{o}}$ & $(\%)$ & $\mathrm{N}^{\mathrm{o}}$ & $(\%)$ \\
\hline \multicolumn{5}{|l|}{$\beta$-Lactamicos } \\
\hline Meropenem & 129 & 99,24 & 1 & 0,76 \\
\hline Amoxicilina + Ácido Clavulânico & 114 & 87,69 & 16 & 12,31 \\
\hline Ceftioflur & 109 & 83,84 & 21 & 16,19 \\
\hline Penicilina $\mathrm{G}$ & 1 & 0,77 & 129 & 99,23 \\
\hline \multicolumn{5}{|l|}{ Sulfonamidas } \\
\hline Trimethoprim + Sulfametoxazol & 106 & 81,54 & 24 & 18,46 \\
\hline Sulfonamida & 61 & 46,92 & 69 & 53,08 \\
\hline \multicolumn{5}{|l|}{ Tetraciclinas } \\
\hline Doxiciclina & 73 & 56,15 & 57 & 43,85 \\
\hline Tetraciclina & 62 & 47,69 & 68 & 52,31 \\
\hline \multicolumn{5}{|l|}{ Pleuromutilinas } \\
\hline Florfenicol & 122 & 93,85 & 8 & 6,15 \\
\hline Cloranfenicol & 121 & 93,07 & 9 & 6,93 \\
\hline \multicolumn{5}{|l|}{ Quinolonas e Fluoroquinolonas } \\
\hline Ciprofloxacina & 113 & 86,93 & 17 & 13,07 \\
\hline Enrofloxacina & 87 & 66,93 & 43 & 33,07 \\
\hline \multicolumn{5}{|l|}{ Aminoglicosídeos } \\
\hline Gentamicina & 114 & 87,69 & 16 & 12,31 \\
\hline
\end{tabular}

A sensibilidade apresentada pelas cepas no presente trabalho em relação as pleuromutilinas pode ser justificada pela alta eficiência dos dois fármacos, o cloranfenicol $(93,1 \%)$ e ao florfenicol $(93,85 \%)$. A eficácia do clorafenicol justifica-se uma vez que seu uso é proibido na medicina veterinária, segundo instrução normativa (IN) $\mathrm{N}^{\circ} 9$ de 23 de junho de 2003.

Contudo, Momtaz \& Jamshidi (2013) ao analisarem cepas de E. coli provenientes de carne de frango coletadas em cinco municípios do Irã, verificaram alta resistência $(77 \%)$ a este antimicrobiano, revelando o uso indiscriminado do cloranfenicol para tratamento de animais e comprovando que este pode resultar no surgimento de cepas resistentes.
O florfenicol por sua vez não é proibido. Relatos de Mendoza (2014) avaliando a resistência antimicrobiana do florfenicol em poedeiras não encontrou relatos de resistência desse fármaco em comparação ao grupo controle. Relata também o uso consciente do fármaco na indústria avícola, o que pode explicar a eficiência deste fármaco no presente resultado.

A gentamicina $(87,7 \%)$ foi o fármaco de escolha para representar os aminoglicosídeos, devido ao seu grande uso na veterinária, a sua acessibilidade e preço baixo, as quinolonas / fluoroquinolonas, são fármacos de primeira escolha no tratamento de aves e bastante usado na avicultura, a ciprofloxacina $(86,9 \%)$ e enrofloxacina $(66,9 \%)$, apesar do uso expressivo desses antimicrobianos, os mesmos 
apresentam frequência elevada. Este fato pode ser explicado pelo uso correto do antimicrobiano e do emprego de protocolo de fácil aplicação. Entretanto como pode ser observado a enrofloxacina já demostra perda da eficiência, levando a acreditar que esse fármaco deve ficar em desuso com o passar do tempo.

Os $\beta$-lactâmicos foi extensamente utilizado na medicina veterinária. O gênero Escherichia coli é naturalmente resistente a penicilina $\mathrm{G}$, portanto, é comumente esperado um resultado de alta resistência de cepa a essa classe de medicamento. Em contrapartida, a alta sensibilidade observada ao meropenem se deve, provavelmente, pela baixa disponibilidade para uso em medicina veterinária.

O meropenem é indicado como alternativa terapêutica de última escolha em casos de infecções graves provocadas por bactérias Gram-negativas resistentes a outros antimicrobianos, devido ao seu amplo espectro de ação contra bactérias da família Enterobacteriaceae e bacilos Gram-negativos não fermentadores da lactose (Shah, 2008). Assim, este princípio, devido suas peculiaridades e sua pouca disponibilidade no mercado, contribuíram para os dados apresentados de $67,88 \%$.

Com relação a eficiência encontrada para a amoxicilina $(87,7 \%)$ acredita-se que sua associação com o ácido clavulânico $(87,7 \%)$ que impede a formação da enzima $\beta$-Lactamase assim conferindo maior eficiência do fármaco. Os resultados de sensibilidade apresentados pelo ceftioflur foram similares aos encontrados na amoxicilina com ácido clavulânico $83,8 \%$, pois por ser uma cefalosporina de $3^{\text {a }}$ geração, possui maior espectro de atuação (Oliveira, 2010).

As sulfonamidas apresentaram sensibilidade baixa $(46,9 \%)$, possivelmente devido ao seu extenso uso na medicina veterinária, pois por muito tempo as drogas deste grupo foram utilizadas como promotores de crescimento na avicultura, o que pode ter contribuído para o surgimento de resistência a esses fármacos.

Já o conjugado trimethoprim + sulfametoxazol obteve sensibilidade de $81,5 \%$, uma vez que o sinergismo dos dois fármacos amplia o espectro de ação e soma da performance.

Os resultados do grupo das tetraciclinas foi o menos eficiente. A doxiciclina e a tetraciclina apresentaram sensibilidade inferior a $60 \%$, justificando a causa da redução do uso destes antimicrobianos na terapêutica de aves. Brito et al. (2011) verificaram que E.coli isoladas de lesões de celulite de frangos de corte oriundo de criações do Paraná também apresentaram resistência enrofloxacina $(62 \%)$, tetraciclina $(21 \%)$, doxiciclina (4\%) e sulfonamida (46\%).

Quanto a susceptibilidade das amostras por estado de origem (Tabela 2), observou-se o estado de Goiás (GO) e Tocantins (TO) apresentaram resultados similares. Enquanto que o Distrito Federal (DF) e São Paulo (SP) apresentaram menor percentual. Nas amostras oriunda do estado de GO e TO, respectivamente, $76 \%$ e $72 \%$, das cepas isoladas foram sensíveis aos antimicrobianos testados. Já o DF e SP apresentaram sensibilidade antimicrobiana de $65 \%$ e $62 \%$, respectivamente. Diferenças estáticas significativas foram encontradas nas frequências observadas nas amostras provenientes de $\mathrm{SP}$ e $\mathrm{DF}$ em relação às amostras do TO e GO ( $p<0,001)$. Esses resultados podem ser explicados pela própria diferença regional, manejo, mercados, clima e a própria característica filogenética individual das cepas de E. coli.

Analisando os dados da tabela 2, verificou-se que as amostras coletadas de aves oriundas do estado de SP apresentaram o maior índice de resistência ceftioflur $(33 \%)$, penicilina $(100 \%)$, tetraciclina (67\%), enrofloxacina (67\%) e trimethoprim + sulfametoxazol (42\%) seguido do DF, já nos estados do GO e TO o perfil de sensibilidade de ambos os estados foram similares, em análise estatística da doxiciclina $(\mathrm{p}=0,012)$ para $\mathrm{GO}$ e a enrofloxacina $(p=0,004)$ para TO, o uso desses fármacos mostraram se eficiente, sugerindo que o uso destes antimicrobianos ainda é recomendado nos respectivos estados. Essa disparidade entre os resultados pode ser explicada pela diferença regional e uma possível pressão de seleção no uso de antimicrobianos nessa região.

De acordo com a tabela 3 as amostras de coração, fígado e suabes do trato respiratório apresentaram sensibilidade relativa de $65 \%, 74 \%$ e $74 \%$ respectivamente. Essa diferença é dada pela própria capacidade individual de difusão dos fármacos, tempo de ação no organismo ou mesmo a capacidade de metabolizar o princípio ativo, conforme CLSI (2012). 
Tabela 2. Susceptibilidade a diferentes antibióticos obtidos a partir da média de cepas de E. coli isoladas de vísceras, trato aéreo superior de aves condenadas oriundas dos estados do Distrito Federal, Goiás, São Paulo e Tocantins, abatidas sob inspeção Federal entre agosto de 2010 a junho de 2012.

\begin{tabular}{ccccccccc}
\hline & \multicolumn{2}{c}{ DF } & \multicolumn{2}{c}{ GO } & \multicolumn{2}{c}{ SP } & \multicolumn{2}{c}{ TO } \\
ME & SEN $^{1}(\%)^{2}$ & RES $^{1}(\%)^{2}$ & SEN $^{1}(\%)^{2}$ & RES $^{1}(\%)^{2}$ & SEN $^{1}(\%)^{2}$ & RES $^{1}(\%)^{2}$ & SEN $^{1}(\%)^{2}$ & RES $^{1}(\%)^{2}$ \\
M & $27(100 \%)$ & $0(0 \%)$ & $66(100 \%)$ & $0(0 \%)$ & $11(92 \%)$ & $1(8 \%)$ & $25(100 \%)$ & $0(0 \%)$ \\
DOX & $9(33 \%)$ & $18(67 \%)$ & $40(61 \%)$ & $26(39 \%)$ & $5(42 \%)$ & $7(58 \%)$ & $19(76 \%)$ & $6(24 \%)$ \\
CTF & $24(89 \%)$ & $3(11 \%)$ & $59(89 \%)$ & $7(11 \%)$ & $8(67 \%)$ & $4(33 \%)$ & $18(72 \%)$ & $7(28 \%)$ \\
FLF & $26(96 \%)$ & $1(4 \%)$ & $63(95 \%)$ & $3(5 \%)$ & $12(100 \%)$ & $0(0 \%)$ & $21(84 \%)$ & $4(16 \%)$ \\
PEN & $1(4 \%)$ & $26(96 \%)$ & $0(0 \%)$ & $66(100 \%)$ & $0(0 \%)$ & $12(100 \%)$ & $0(0 \%)$ & $25(100 \%)$ \\
CIP & $20(74 \%)$ & $7(26 \%)$ & $61(92 \%)$ & $5(8 \%)$ & $10(83 \%)$ & $2(17 \%)$ & $22(88 \%)$ & $3(12 \%)$ \\
TET & $9(33 \%)$ & $18(67 \%)$ & $32(48 \%)$ & $34(52 \%)$ & $4(33 \%)$ & $8(67 \%)$ & $17(68 \%)$ & $8(32 \%)$ \\
ENR & $14(52 \%)$ & $13(48 \%)$ & $54(82 \%)$ & $12(18 \%)$ & $4(33 \%)$ & $8(67 \%)$ & $15(60 \%)$ & $10(40 \%)$ \\
CLO & $24(89 \%)$ & $3(11 \%)$ & $62(94 \%)$ & $4(6 \%)$ & $12(100 \%)$ & $0(0 \%)$ & $23(92 \%)$ & $2(8 \%)$ \\
SXT & $21(78 \%)$ & $6(22 \%)$ & $57(86 \%)$ & $9(14 \%)$ & $7(58 \%)$ & $5(42 \%)$ & $21(84 \%)$ & $4(16 \%)$ \\
SSS & $10(37 \%)$ & $17(63 \%)$ & $37(56 \%)$ & $29(44 \%)$ & $2(17 \%)$ & $10(83 \%)$ & $12(48 \%)$ & $13(52 \%)$ \\
GEN & $19(70 \%)$ & $8(30 \%)$ & $62(94 \%)$ & $4(6 \%)$ & $11(92 \%)$ & $1(8 \%)$ & $22(88 \%)$ & $3(12 \%)$ \\
AMC & $25(93 \%)$ & $2(7 \%)$ & $60(91 \%)$ & $6(9 \%)$ & $10(83 \%)$ & $2(17 \%)$ & $19(76 \%)$ & $6(24 \%)$ \\
\hline Total & $229(65 \%)$ & $122(35 \%)$ & $653(76 \%)$ & $205(24 \%)$ & $96(62 \%)$ & $60(38 \%)$ & $234(72 \%)$ & $91(28 \%)$ \\
\hline
\end{tabular}

*1. Número de cepas, sensíveis ou resistentes em cada origem de isolamento; 2. Porcentagem calculada em relação às frequências examinadas em cada origem de isolamento; 3. Porcentagem calculada em relação ao total de cepas analisadas; DF, Distrito Federal; GO, Goiás; SP, São Paulo; TO, Tocantins; MEM, meropenem; DOX, doxiciclina; CTF, ceftioflur; FLF, florfenicol; PEN, penicilina G; CIP, ciprofloxacina; TET, tetraciclina; ENR, enrofloxacina; CLO, cloranfenicol; STX, trimethoprim + sulfametoxazol; SSS, sulfonamida; GEN, gentamicina; AMC, amoxicilina + ácido clavulânico.

Tabela 3. Susceptibilidade a diferentes antibióticos obtidos a partir da média de cepas de E. coli isoladas de vísceras e trato aéreo superior de aves condenadas e abatidas sob inspeção Federal entre agosto de 2010 a junho de 2012.

\begin{tabular}{ccccccc}
\hline & \multicolumn{2}{c}{ Coração } & \multicolumn{2}{c}{ Fígado } & \multicolumn{2}{c}{ Suabe } \\
& SEN $^{1}(\%)^{2}$ & $\operatorname{RES}^{1}(\%)^{2}$ & SEN $^{1}(\%)^{2}$ & $\operatorname{RES}^{1}(\%)^{2}$ & SEN $^{1}(\%)^{2}$ & RES $^{1}(\%)^{2}$ \\
\cline { 2 - 6 } MEM & $32(100 \%)$ & $0(0 \%)$ & $29(97 \%)$ & $1(3 \%)$ & $68(100 \%)$ & $0(0 \%)$ \\
CTF & $13(41 \%)$ & $19(59 \%)$ & $14(47 \%)$ & $16(53 \%)$ & $46(68 \%)$ & $22(32 \%)$ \\
FLF & $27(84 \%)$ & $5(16 \%)$ & $28(93 \%)$ & $2(7 \%)$ & $54(79 \%)$ & $14(21 \%)$ \\
PEN & $30(94 \%)$ & $2(6 \%)$ & $30(100 \%)$ & $0(0 \%)$ & $62(91 \%)$ & $6(9 \%)$ \\
CIP & $24(75 \%)$ & $8(25 \%)$ & $27(90 \%)$ & $3(10 \%)$ & $62(91 \%)$ & $6(9 \%)$ \\
TET & $12(37 \%)$ & $20(63 \%)$ & $12(40 \%)$ & $18(60 \%)$ & $38(56 \%)$ & $30(44 \%)$ \\
ENR & $18(56 \%)$ & $14(44 \%)$ & $19(63 \%)$ & $11(37 \%)$ & $50(74 \%)$ & $18(26 \%)$ \\
CLO & $29(91 \%)$ & $3(9 \%)$ & $29(97 \%)$ & $1(3 \%)$ & $63(93 \%)$ & $5(7 \%)$ \\
SXT & $23(72 \%)$ & $9(28 \%)$ & $25(83 \%)$ & $5(17 \%)$ & $58(85 \%)$ & $10(15 \%)$ \\
SSS & $12(37 \%)$ & $20(63 \%)$ & $18(60 \%)$ & $12(40 \%)$ & $31(46 \%)$ & $37(54 \%)$ \\
GEN & $22(69 \%)$ & $10(31 \%)$ & $29(97 \%)$ & $1(3 \%)$ & $63(93 \%)$ & $5(7 \%)$ \\
AMC & $28(88 \%)$ & $4(13 \%)$ & $26(87 \%)$ & $4(13 \%)$ & $60(88 \%)$ & $8(12 \%)$ \\
\hline Total & $\mathbf{2 7 0 ( 6 5 \% )}$ & $\mathbf{1 4 6 ( 3 5 \% )}$ & $\mathbf{2 8 7}(\mathbf{7 4 \%})$ & $\mathbf{1 0 3 ( 2 6 \% )}$ & $\mathbf{6 5 5 ( 7 4 \% )}$ & $\mathbf{2 2 9}(\mathbf{2 6 \%})$ \\
\hline
\end{tabular}

*1. Número de cepas, sensíveis ou resistentes em cada origem de isolamento; 2. Porcentagem calculada em relação às frequências totais examinados em cada origem de isolamento; 3. Porcentagem calculada em relação ao total de cepas analisadas; DF, Distrito Federal; GO, Goiás; SP, São Paulo; TO, Tocantins; MEM, MEM, meropenem; DOX, doxiciclina; CTF, ceftioflur; FLF, florfenicol; PEN, penicilina G; CIP, ciprofloxacina; TET, tetraciclina; ENR, enrofloxacina; CLO, cloranfenicol; STX, trimethoprim + sulfametoxazol; SSS, sulfonamida; GEN, gentamicina; AMC, amoxicilina + ácido clavulânico. 
O fígado e coração são vísceras bastante comercializadas em supermercados, açougues e similares com vistas ao fornecimento de carne. Por se tratar de um produto destinado ao consumo humano, torna-se importante à avaliação microbiológica e o conhecimento do processo de resistência microbiana das cepas isoladas destes produtos.

Nas amostras de fígado e coração, o meropenem, ceftioflur, florfenicol, ciprofloxacina, cloranfenicol, trimethoprim + sulfametoxazol, gentamicina e amoxicilina + ácido clavulânico, apresentaram o melhor desempenho de sensibilidade a amostras testadas de fígado e suabe de trato aéreo superior. Contudo, ao analisar a associação da eficiência dos fármacos com relação aos tipos de amostras clinicas, foi observado efeito significativo da Gentamicina $(p=0,002)$ sobre as amostras do coração, sugerindo a eficiência do produto apesar da frequência de sensibilidade ser inferior a $70 \%$.

Com base nas tabelas anteriores, pode se observar uma grande variação no perfil de sensibilidade, seja pela procedência da amostra ou a origem das cepas. Em parte essa grande variação pode ser explicada pela heterogeneidade dos sistemas de produção adotado no Brasil, clima, manejo e características de mercado (Aboklaish et al., 2014; Hsu et al., 2014; Oltramari et al., 2012). Entretanto, existe uma variação normal filogenética de cepas de $E$. coli, que podem ser resistente a um tipo de antimicrobianos, ou mesmo a um grupo de antimicrobianos (Dens, 2003; Hammerum \& Lester \& Heuer, 2010).

Outro aspecto a ser considerado, é a utilização indiscriminada de antimicrobianos, que favorece a seleção de resistência a antimicrobianos (Mota et al., 2005). Ademais, um dos maiores desafios na produção animal atual é a busca de alternativas para se reduzir o uso de antimicrobianos como promotores de crescimento, principalmente em consequência das crescentes pressões impostas por legislações de países que importam produtos de origem animal do Brasil, que proíbem a inclusão de antimicrobianos nas dietas de frangos de corte (Medeiros, 2009).

A avaliação do perfil de resistência tem grande importância devido aos fármacos utilizados na medicina humana e veterinária pertencerem as mesmas classes de drogas. Ewers et al. (2009) ao estudarem 367 cepas de E. coli, relatam a importância deste agente no setor avícola, e sua capacidade de colonizar o trato gastrointestinal e vísceras, além da grande concentração de cepas patogênicas no intestino de frangos, e sua capacidade de disseminação de aves para humanos ou vice-versa.

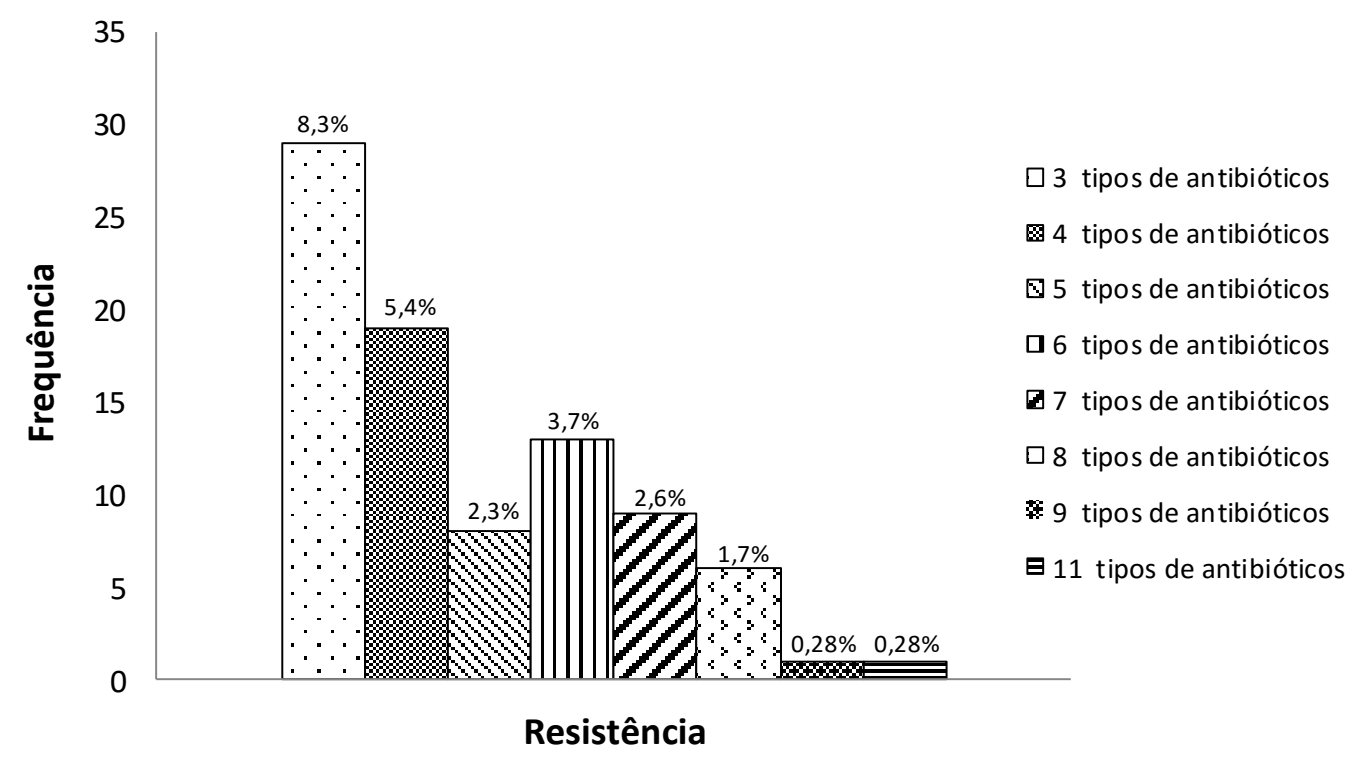

Figura 1. Frequência de ocorrência de multirresistência em 130 isolados de Escherichia coli isoladas de vísceras e trato aéreo superior de aves condenadas e abatidas sob Inspeção Federal entre agosto de 2010 a junho de 2012.

Pelos resultados observou-se que $24,56 \%$ das cepas isoladas apresentaram multirresistência aos antimicrobianos testados (Figura 1). Apesar de não haver diferença estatística entre os estados, merece destaque o DF, uma vez que foi o único a apresentar resistência a nove $(0,28 \%)$ e onze
$(0,28 \%)$ antimicrobianos. Esse fato é explicado devido à alta capacidade da $E$. coli em transferir o seu material genético para outros microorganismos, acentuado por sua concentração e capacidade de sobrevivência no trato 
gastrointestinal (Aboklaish et al., 2014; Hsu et al., 2014).

Lima-Filho et al., 2013 avaliando cepas de E. coli obtidas de frangos, observaram multirresistência a no mínimo quatro antimicrobianos testados em $40,7 \%$ e as amostras que foram resistentes a oito e onze antimicrobianos representaram $22,2 \%$.

Estes resultados demonstram que dentro da produção avícola, apesar de existir um controle sobre a utilização de antimicrobianos, é interessante um acompanhamento periódico dos resultados da terapêutica utilizada na produção, pela grande contribuição da avicultura no mercado internacional.

\section{CONCLUSÃO}

Os dados apresentados nesse estudo revelam que a utilização dos antimicrobianos testados ainda não se tornou um problema para a avicultura em TO, GO, DF e SP, pois a maioria das drogas foram eficientes sobre E. coli. Contudo, não se deve negligenciar a utilização de antimicrobianos, pois o perfil de resistência microbiana é mutável podendo surgir cepas bacterianas multirresistentes, o que dificultaria o tratamento de animais com infecção primária ou secundária por E. coli.

Assim, nas condições experimentais deste trabalho, são indicados para tratamento de frango com E. coli apenas o ceftioflur, florfenicol, ciprofloxacina, trimethoprim + sulfametoxazol, gentamicina, amoxicilina + ácido clavulânico.

\section{AGRADECIMENTOS}

Ao CNPq e Secretaria de Ciência e Tecnologia do Estado do Tocantins (SECT-TO) por disponibilizar recursos financeiros e a Universidade Federal do Tocantins (UFT/PROPESQ) para realização do projeto.

\section{REFERÊNCIAS}

ABOKLAISH, A. F.; DORDET-FRISONI, E.; CITTI, C.; TOLEMAN, M. A.; GLASS, J. I.; SPILLER, O. B. Random insertion and gene disruption via transposon mutagenesis of Ureaplasma parvum using a mini-transposon plasmid. International Journal of Medical Microbiology, v.304, n.8, p.1218-1225, 2014

Agrostat - AgroStat Brasil, 2015. Disponível em <http://sistemasweb.agricultura.gov.br/pages/AGROSTAT.html >. Acesso em: 23 ago. 2015.

BRITO, K. C. T.; JAENISCH, F. R. F.; OLIVEIRA, G. A.; SOARES, B. D.; BRITO, B. G. Resistência antimicrobiana e patogenicidade de amostras de escherichia coli isoladas de lesões de celulite em frangos. In. XXII Congresso latinoamericano de avicultura, Buenos Aires - Argentina, Congresso... Cepa, 2011.
CÁRDENAS-PEREA, M. E; CRUZ, O. R. GÁNDARARAMÍREZ, L. J. L.; PÉREZ-HERNÁNDEZ, M. A. Factores de virulencia bacteriana: la "inteligencia" de lasbacterias. Elementos, v.21, n.94, p.35-43, 2014.

CHANSIRIPORNCHAI, N. Antimicrobial Sensitivity of Avian Pathogenic Escherichia coli (APEC) Isolated from Chickens During 2007-2010. Thai Journal of Veterinary Medicine, v.41, n.4, p.519-522, 2011

CLSI - Clinical and Laboratory Standards Institute (CLSI) Performance Standards for Antimicrobial Susceptibility Testing; Twenty-Second Informational Supplement. M100S22, v.32, n.3, 2012

DENS, F. W. An alternative for antibiotic se in poultry: probiotics. Revista Brasileira de Ciência Avícola, v. 5, n. 2, p. 75-97, 2003.

DHEILLY, A.; LE DEVENDEC, L.; MOURAND, G.; JOUY, E.; KEMPF, I. Antimicrobial resistance selection in avian pathogenic E. coli during treatment. Veterinary Microbiology, v.166, n.3-4, p.655-658, 2013.

EWERS, C.; ANTÃO, E. M.; DIEHL, I.; PHILIPP, H. C.; WIELER, L. H. Intestine and Environment of the Chicken as Reservoirs for Extraintestinal Pathogenic Escherichia coli Strains with Zoonotic Potential. Applied and Environmental Microbiology, v.75, n.1, n.184-192, 2009.

FIORENTINO, G.; BROSSI, L.; AMELONG, I.; CAMPANATTI, C. As Oito Grandes Tendências de Crescimento Até 2020, [S.1]: Equipe Editorial Global p. 01-54, 2012.

HAMMERUM, A. M.; LESTER, C. H.; HEUER, O. E. Antimicrobial-Resistant Enterococci in Animals and Meat: A Human Health Hazard? Foodborne Pathogens and Disease, v. 7, n. 10, p. 1137-1146, 2010.

HSU, J. T.; CHEN, C. Y.; YOUNG, C. W.; CHAO, W. L.; LI, M. H.; LIU, Y. H.; LIN, C. M.; YING, C Prevalence of sulfonamide-resistant bacteria, resistance genes and integronassociated horizontal gene transfer in natural water bodies and soils adjacent to a swine feedlot in northern Taiwan. Journal of Hazardous Materials, v.277, p.34-43, 2014.

KRIEG, N. R.; HOLT, J. G. (Ed.). Bergey's manual of systematic bacteriology. Baltimore: Williams \& Wilkins, v.1, p.964, 1984.

LEVIN, BRUCE R.; BAQUERO, FERNANDO; JOHNSEN, PÅL J. A model-guided analysis and perspective on the evolution and epidemiology of antibiotic resistance and its future. Current Opinion in Microbiology, v.19, p.83-89, 2014.

LIMA-FILHO, J. V.; MARTINS, L. V.; DE OLIVEIRA NASCIMENTO, D. C.; VENTURA, R. F.; BATISTA, J. E. C.; SILVA, A. F. B.; RALPHA, M. T.; VAZA, R. V.; RABELLOB, C. B. V.; SILVAC, I. M. M.; EVÊNCIO-NETOC, J. Zoonotic potential of multidrug-resistant extraintestinal pathogenic Escherichia coli obtained from healthy poultry carcasses in Salvador, Brazil. The Brazilian Journal of Infectious Diseases, v. 17, n. 1, p. $54-61,2013$

MACHADO, L. S.; NASCIMENTO, E. R.; PEREIRA, V. L. A.; ALMEIDA, D. O.; ABREU, D. L. C.; GOUVÊA, R.. PCR na detecção de gene fel a de Escherichia coli em frangos de corte condenados por aerossaculite pela inspeção sanitária federal. Arquivos do Instituto Biológico. v. 80, n. 2, p. 145-149, 2013.

MEDEIROS, P. T.; PADILHA, M. T. S.; PADILHA, J. C. F.; ESPÍNDOLA, F.; MAGGIONI, R. Efeito de promotores de crescimento alternativos no desempenho e no custo de produção de frangos de corte. Biotemas, v. 22, p. 157-163, 2009. 
MENDOZA, G. D. T. Efecto de los tratamientos con florfenicol, tilosina enrofloxacino y oxitetraciclina en gallinas ponedoras sobre los perfiles de sensibilidad de cepas Escherichia coli aisladas de la microbiota intestinal. 2014. f29. Universidad de Chile -Facultad de Ciencias Veterinarias y Pecuarias Escuela de Ciencias Veterinarias. 2014.

MENIN, A.; RECK, C.; SOUZA, D. D.; KLEIN, C.; VAZ, E. Agentes bacterianos enteropatogênicos em suínos de diferentes faixas etárias e perfil de resistência a antimicrobianos de cepas de Escherichia coli e Salmonella spp, Ciência Rural, v.38, n.6, p.687-693, 2008.

MOMTAZ, H.; JAMSHIDI, A. Shiga toxin-producing Escherichia coli isolated from chicken meat in Iran: Serogroups, virulence factors, and antimicrobial resistance properties. Poultry science, v.92, n.5, p.1305-1313, 2013.

MOTA, R. A.; DA SILVA, K. P. C.; DE FREITAS, M. F. L.; PORTO, W. J. N.; DA SILVA, L. B. G. Utilização indiscriminada de antimicrobianos e sua contribuição a multirresitência bacteriana. Brazilian Journal of Veterinary Research and Animal Science, v. 42, n. 6, p. 465-470, 2005.

OLIVEIRA, M. J. C. P. Estudo de resistência da bactéria Escherichia coli a antimicrobianos em infecções urinárias na população da Região Autónoma da Madeira. 2010. 64f. Dissertação (Mestrado), Universidade da Madeira, Funchal, 2010. Disponível em < http://repositorio.uma.pt/handle/10400.13/586 >. Acesso em: 24 fer. 2015.

OLTRAMARI, K.; RIOS, M. C.; BERGAMASCO, R.; JUNIOR, M. M.; ZANELLA, G. N.; MADRONA, G.; MIKCHA, J. M. G. Resistência a Antimicrobianos em Escherichia coli isolada de leite pasteurizado. Revista Tecnológica, p. 75-82, 2012.

RAHIMI, M. Antibioresistance Profile of Avian pathogenic Escherichia coli Isolates Recovered from Broiler Chicken Farms with Colibacillosis in Kermanshah Province, Iran. Global Veterinaria, v. 10, n. 4, p. 447-452, 2013.

ROCHA, T. M. Fatores de virulência de Escherichia coli patogênica para aves. 2010. f31. Tese - Universidade Federal de Goiás, Goiânia, 2010. Disponível em <http://portais.ufg.br/uploads/67/original_Tatiane_Rocha_1c.pdf >. Acesso em: 22 mar. 2014.

SABERFAR, E.; POURAKBARI, B.; CHABOKDAVAN, K.; DOLATSHAHI, F. T. Antimicrobial Susceptibility of Escherichia coli Isolated from Iranian Broiler Chicken Flocks, 2005-2006. The Journal of Applied Poultry Research, v. 17, n. 2 , p. $302-304,2008$.

SAHOO, T. K.; SAHOO, L.; SARANGI, L. N.; PANDA, S. K.; PANDA, H. K. Prevalence, Isolation, Characterisation and Antibiogram Study of Pathogenic Escherichia coli from Different Poultry Farms of Odisha. Journal of Advanced Veterinary Research, v.2, p.169-172, 2012.

SALEHI, T. Z.; BONAB, S. F. Antibiotics Susceptibility Pattern of Escherichia coli Strains Isolated from Chickens with Colisepticemia in Tabriz Province, Iran. International Journal of Poultry Science, v. 5, n. 7, p. 677-684, 2006.

SHAH, P. M. Parenteral carbapenemas. Clinical Microbiology and Infection. v. 14, n. 11, p. 175-180, 2008

SOUZA, A. D.; SOUZA, A. D.; ASTOLFI FILHO, S.; BELÉM PINHEIRO, M. L.; SARQUIS, M. I. D. M.; PEREIRA, J. O. Atividade antimicrobiana de fungos endofíticos isolados de plantas tóxicas da amazônia: Palicourea longiflora (aubl.) rich e Strychnos cogens bentham. Acta amazônica, v. 34, n. 2, p. $185-$ 195, 2004.
WEBER, T.; CHARUSANTI, P.; MUSIOL-KROLL, E. M.; JIANG, X.; TONG, Y.; KIM, H. U.; LEE, S. Y. Metabolic engineering of antibiotic factories: new tools for antibiotic production in actinomycetes. Trends in Biotechnology, v.33, n.1, p.15-26, 2015. 